\title{
Fundos de Pensão como Formadores de Poupança Interna: uma Alternativa para o Financiamento da Atividade Econômica
}

\author{
Hudson Fernandes Amaral \\ Caroline Sales Issa Vilaça \\ Camila Figueirêdo Marques Barbosa \\ Valéria Gama Fully Bressan
}

\begin{abstract}
Resumo
A geração de poupança interna e a ampliação do investimento produtivo é condição para alcançar e manter taxas de crescimento econômico compatíveis com o desenvolvimento social. Os fundos de pensão, com os recursos disponíveis para investir, possibilitam alavancar o desenvolvimento de um país na medida em que canalizam esses recursos para o setor produtivo. Diante de tal perspectiva, o nosso estudo propõe analisar o desempenho das aplicações em renda variável desses fundos, aqui considerados investimento produtivo, por meio do Capital Asset Pricing Model (CAPM). Esse modelo se presta a explicar o comportamento dos preços dos títulos e fornecer mecanismos de avaliação do investimento realizado em relação ao risco e retorno da carteira. A partir da metodologia proposta, verificou-se que os investimentos em ações incorreram em retornos superiores aos esperados, gerando por um lado maior valor agregado ao fundo e, por outro, um incremento da poupança interna do país, respaldado pela aplicação de recursos no setor produtivo.
\end{abstract}

Palavras-chaves: fundos de pensão; poupança interna; investimento produtivo; Capital Asset Pricing Model.

\begin{abstract}
The production of domestic savings and the amplification of the productive investment are the conditions to reach and to maintain rates of economical growth compatible with social development. The pension funds, with the available resources to invest, make possible to leverage the development of a nation, as they channel these resources for the country's productive sector. At this perspective, this study intends to analyze the performance of the investments in variable income of these funds, here considered productive investments, through the Capital Asset Pricing Model (CAPM). This model is predisponent to explain the behavior of the prices of the titles and to supply mechanisms of evaluation of the investment accomplished - in relation to the risk and return of the portfolio. Starting from the proposed methodology, it was verified that the investments in stocks incurred in superior returns than the expected ones, generating, by one hand, a larger aggregated value to the fund, and by the other, an increment of the intern savings of the country, backed by the application of resources in the productive section.
\end{abstract}

Key words: pension funds; domestic savings; productive investment; Capital Asset Pricing Model. 


\section{INTRODUÇÃO}

A geração de um volume mínimo de poupança interna de forma continuada é um dos principais fatores de sustentabilidade do crescimento de uma economia. Esta poupança viabiliza os investimentos, que são canalizados ao setor produtivo por meio do sistema financeiro. Nesse contexto, devido à magnitude das somas administradas, os investidores institucionais, agrupados em fundos mútuos de investimentos, seguradoras e entidades fechadas de previdência privada, desempenham importante papel na formação de poupança interna.

Entretanto, na prática, nem toda a poupança é destinada a investimentos na Formação Bruta de Capital Fixo, e somente estes podem alavancar o processo de crescimento econômico. Diante desta perspectiva, torna-se importante otimizar a alocação dos recursos dos fundos de pensão, o que possibilitaria maior alavancagem desse crescimento. Por outro lado, deve-se avaliar que o fim último dos fundos de pensão é garantir a concessão de benefícios aos seus participantes, o que implica empregar os recursos nas modalidades mais rentáveis, sempre levando-se em consideração o risco.

Nesse sentido, o presente estudo propõe estimar os retornos dos investimentos em renda variável, aqui considerados como investimento produtivo, e contrastálos com os respectivos retornos reais dos fundos de pensão, ou seja, busca-se responder à seguinte questão: o retorno real da carteira de ações observado dos fundos de pensão superou o retorno estimado no período de janeiro de 1999 a março de 2001, desempenhando papel contribuinte na formação de poupança interna e na aplicação de recursos no setor produtivo?

Para responder ao problema de pesquisa, analisou-se o desempenho da carteira de investimentos em ações dos fundos de pensão no período de janeiro de 1999 a março de 2001. Identificou-se a composição das carteiras de investimentos, mensurou-se a rentabilidade mensal das carteiras, avaliou-se o retorno médio das carteiras de ações das entidades no período total de análise (abril de 1999 a março de 2001), bem como nos subperíodos propostos (abril de 1999 a março de 2000 e abril de 2000 a março de 2001); por fim, mensurou-se o retorno estimado mensal e dos períodos propostos dessas carteiras por meio da aplicação do Capital Asset Pricing Model, CAPM.

O artigo apresenta, primeiramente, uma revisão de literatura relacionada ao problema da pesquisa. A seguir, explica-se o modelo Capital Asset Pricing Model, 
que serviu como base para descrever o comportamento dos preços dos títulos e fornecer mecanismos de avaliação do investimento proposto ou realizado em relação ao risco e retorno de toda a carteira. No tópico seguinte, expõem-se os dados utilizados e os resultados obtidos; finalmente, são apresentadas as conclusões.

\section{Fundos de Pensão}

Segundo Baima (1998), é de extrema importância o papel desempenhado pelos fundos de pensão, tanto do ponto de vista social, pelos benefícios que proporcionam aos seus participantes e pelo papel que desempenham na criação de empregos, quanto do econômico, por serem o mais importante investidor institucional, dispondo de recursos aplicados a longo prazo, essenciais à formação bruta de capital fixo da economia, à democratização do capital das empresas, ao desenvolvimento do programa de privatização e à geração de poupança interna.

Os fundos de pensão são os principais detentores nacionais de liquidez domésticos, sendo que suas aplicações vêm crescendo nos últimos anos. Seus investimentos, passaram de 3,3\% do PIB, em 1990, para 14,45\%, em 2001 (Gráfico 1), demonstrando o crescimento dos ativos disponíveis para investimento em relação ao PIB brasileiro. No entanto os fundos de pensão no Brasil estão longe de assumirem a representatividade que têm em outros países. Na Holanda, o valor dos ativos dos fundos de pensão é maior do que o PIB, nos Estados Unidos é próximo de $80 \%$ (Tabela 1 ).

\section{Gráfico 1: Evolução dos Ativos das EFFP's em relação ao PIB Brasileiro (\%)}

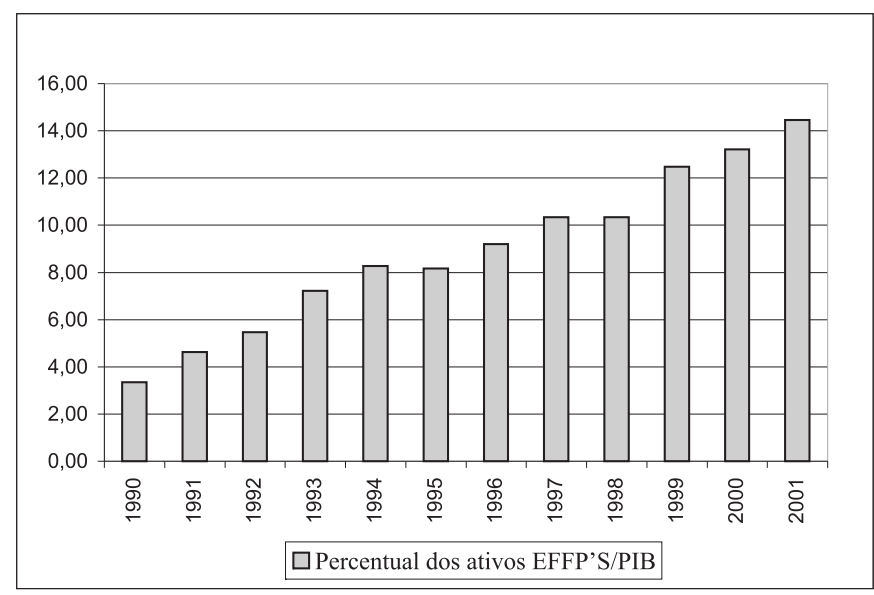

Fonte: França, 2002, p.66. 
Tabela 1: Percentual dos Ativos dos Fundos de Pensão em Relação ao PIB

\begin{tabular}{c|c}
\hline País & $\begin{array}{c}\text { Ativos dos fundos } \\
(\% / \text { PIB })\end{array}$ \\
\hline Holanda & 118 \\
Suíça & 117 \\
Dinamarca & 84 \\
Reino Unido & 83,7 \\
Estados Unidos & 78 \\
Japão & 72 \\
Canadá & 48 \\
Chile & 44,3 \\
Suécia & 43 \\
\hline
\end{tabular}

Fonte: elaboração dos autores baseada em dados da Abrapp, disponível em: http://www.abrapp.org.br/estatisticas/internaci onal/estatistica_regional/estatisticas_regionais. htm. Acesso em 11 set. 2002.

\section{Riscos dos Fundos de Pensão}

Os principais riscos incorridos pelos fundos de pensão se reportam ao risco atuarial e ao risco de mercado. O equilíbrio atuarial se estende além do equilíbrio financeiro. Este requer que as despesas e demais desembolsos correntes sejam pelo menos igualados às receitas correntes somadas às provisões ou outros tipos de reservas acumuladas. Já o equilíbrio atuarial exige, além disto, que às despesas e demais desembolsos futuros correspondam fontes presumivelmente capazes de, pelo menos, se equipararem aos gastos. Portanto o risco atuarial se relaciona às estimativas inexatas da taxa de mortalidade dos beneficiários (Pereira et al.,1997).

O risco de mercado, por sua vez, consiste no risco de que os ativos acumulados não sejam suficientes para cobrir os desembolsos prometidos. Modernas teorias de carteira sugerem que a diversificação da carteira pode reduzir o risco que surge dos diferentes desempenhos de empresas e indústrias individuais, mas não pode reduzir o risco decorrente do mau desempenho da economia como um todo, ou seja, o risco sistemático ou não diversificável, medido pelo coeficiente beta. Portanto o gerenciamento do risco de mercado mostra-se como uma ação de extrema relevância na gestão dos recursos dos fundos de pensão. Tal atividade 
ganha ainda mais importância para os planos previdenciários de benefício definido, cujos administradores devem buscar incessantemente o necessário equilíbrio econômico-financeiro entre os ativos e o respectivo passivo atuarial (Federación Iberoamericana de Bolsas de Valores - FIABV, 2002).

As políticas de investimento dos fundos de pensão variam significativamente entre os países, como reflexo de distintos contextos institucionais e regulatórios, do grau de desenvolvimento e diversificação dos mercados de capitais domésticos e de fatores macroeconômicos, tais como: taxa de inflação, nível do déficit público, tendências da taxas de juros, e também do nível de rentabilidade das empresas que buscam recursos nos mercados financeiros. Embora o que determine a estratégia de investimentos dos fundos seja a interação de todos esses elementos, os requisitos e as regras para os investimentos dos fundos, fixados pelos órgãos de supervisão, aparecem como o principal condicionante da distribuição das carteiras de ativos de fundos de pensão (FIABV, 2002).

No Brasil, o Conselho Monetário Nacional (CMN) define os limites máximos para os investimentos nas diferentes categorias de ativos dos fundos de pensão, com o intuito de assegurar que as instituições não incorram em riscos excessivos, concentrando as aplicações em apenas um tipo de ativo ou adquirindo ativos de alto risco.

\section{Fundos de Pensão e Investimento Produtivo}

Segundo Shaw (1973 apud Stuart, 2000) e Mckinnon (1973 apud Studart, 2000), a melhor política para o incremento da poupança e investimento é, na verdade, a falta de política. Se existe um mercado perfeito, uma política em direção à liberalização financeira é a única política necessária e a melhor maneira para se alcançar elevados níveis de poupança e investimento. No que diz respeito aos fundos de pensão, a conclusão é que se eles são livres para investir naquilo que proporciona retornos mais altos, em ambiente competitivo isto geraria maior nível de poupança agregada e investimento.

No entanto, de acordo com Studart (2000), a teoria neokeynesiana e a liberalização econômica falham ao desconsiderar a importância da estrutura financeira no financiamento do processo produtivo. Muitas experiências de liberalização financeira - que na teoria geraria uma intermediação financeira mais flexível e mercados mais eficientes - e de altos retornos em ativos financeiros, não resultaram em direcionamento a elevados níveis de poupança agregada e investimento. Cintra (2000), por meio da análise dos processos de 
liberalização financeira, interna e externa entre 1974 e 1982, dos países do Cone Sul (Argentina, Chile e Uruguai), os primeiros a adotarem esse modelo, defende que taxas de juros elevadas e políticas financeiras liberalizantes não provocam aumento de poupança, muito menos de investimento. Segundo este autor, a desregulamentação, elevando a taxa de juros, pode ampliar a "poupança financeira”, ou seja, os recursos financeiros não são canalizados para o investimento produtivo, mas ficam circulando numa órbita financeira, sob a forma de fundos de curto prazo e títulos da dívida pública e privada. $\mathrm{O}$ autor ressalta ainda que os problemas do subdesenvolvimento decorrem da ausência de mecanismos de financiamento, bem como das dificuldades de canalizar esses recursos para projetos de investimento.

Segundo Miranda et al. (1998), a ampliação do investimento produtivo interno é condição para alcançar e manter taxas de crescimento econômico compatíveis com o desenvolvimento social. Os fundos de pensão podem atuar como agentes do desenvolvimento econômico, ao investirem seus recursos de forma produtiva; entretanto não existe consenso sobre o que caracteriza o investimento produtivo.

Segundo Matijascic (1994), os fundos de pensão somente devem ser considerados investidores produtivos na medida em que seus recursos sejam destinados a investimentos que visem ao aumento da capacidade produtiva. Assim, o aumento da participação dos fundos de pensão no mercado de capitais concorreria para melhorar as condições de financiamento das empresas domésticas, se estes recursos fossem direcionados para as aplicações realizadas no mercado primário.

Outra linha de pensamento defende que os fundos de pensão realizam investimentos produtivos ao terem em suas carteiras ações de empresas, não sendo necessário que a compra das ações seja feita na emissão primária dos títulos. Segundo Castro et al. (1994), ao comprar títulos no mercado secundário, os fundos estão incentivando os negócios em bolsas de valores, estimulando a emissão de novas ações ou até mesmo a abertura de capital. Dessa maneira, segundo a FIABV (2002), o elemento chave desse ciclo é a liquidez. A demanda extra por títulos, advinda de uma participação maior dos fundos de pensão, elevaria as taxas preço/lucro, provocando uma redução no custo de captação de recursos por meio da emissão de ações. Neste contexto, de acordo com o International Finance Corporation (2002 apud FIABV, 2002), organismo financeiro de investimento vinculado ao Banco Mundial, as empresas já listadas são encorajadas a levantar mais recursos, enquanto outras são atraídas para o mercado de capitais. Este órgão destaca o aumento do número de companhias listadas como sendo um dos elementos que comprovam o efeito dinamizador dos fundos. 
Neste estudo, assumiu-se como investimento produtivo os investimentos em ações. Logo, toda aplicação dos fundos de pensão em ações, mesmo que não tenha proporcionado o aumento da capacidade instalada, ou que esses fundos não tenham tido o poder de decisão nas estratégias das empresas, foi considerada investimento produtivo.

Vale ressaltar que a viabilidade de assumir-se que investimentos produtivos sejam aqueles em que os fundos de pensão adquirem partes de empresas, quer por meio de ações negociadas em bolsa, quer por meio de emissão primária, se deve ao fato da existência de certa facilidade de acesso às informações sobre esse tipo de investimento, ao passo que as informações sobre os investimentos dos fundos nas compras de ações no mercado primário não se encontram prontamente disponíveis.

\section{Fundos de Pensão e Mercado de Capitais}

De acordo com Motta (2001), o mercado de capitais é um mecanismo fundamental para a formação e alocação de capital de forma eficiente e no montante adequado para o financiamento do crescimento econômico. Um mercado de capitais forte traz benefícios diretos para a atividade econômica. Por um lado, aumenta as alternativas de investimento, reduz seu custo e, de forma combinada, significa mais crescimento efetivo. Por outro lado, eleva a competitividade da economia como um todo.

Segundo FIABV (2002), um dos traços marcantes do desenvolvimento recente dos mercados financeiros nos países desenvolvidos é a importância crescente dos investidores institucionais - notadamente os fundos de pensão e os fundos mútuos de investimento - como mobilizadores de poupança. E são as ações e os títulos negociáveis de longo prazo, transacionados no mercado de capitais, que constituem os ativos financeiros mais adequados a esses intermediários, que procuram investir em ativos que garantam um fluxo estável de receitas compatível com seus compromissos de geração de renda contratual. Nesse contexto, os fundos de pensão constituem parte importante desse padrão de financiamento, na medida em que eles detêm grande parcela dos investimentos diretos em bolsa.

Motta (2001) ressalta ainda que há correlação entre mercado de capitais forte e a solvência dos fundos de pensão. A existência de melhores alternativas de investimento permite que os administradores dos fundos previdenciários obtenham maior retorno na carteira, reduzam o risco e aumentem a credibilidade dos fundos, resultando em melhores aposentadorias. 
Enfim, na estrutura de financiamento, os fundos de pensão têm importante participação nos mercados de capitais e terminam por agir como grandes investidores. Graças ao desenho desses mercados, eles têm considerável espaço de atuação, na medida em que operam gerindo grandes somas de capital e se colocam entre os principais atores que acabam por influir na dinâmica dos mercados.

\section{Desempenho dos Fundos de Pensão: Capital Asset Pricing MODEL}

Os dois determinantes básicos do preço de um ativo são o risco e o retorno. Assim, as principais decisões financeiras devem ser vistas em termos de retorno esperado, risco esperado e seu impacto combinado ao preço do ativo.

Segundo Pereira et al. (1997), para avaliar o desempenho de um fundo de pensão, é necessário avaliar sua taxa de retorno e compará-la à rentabilidade de uma carteira de referência que tenha um risco igual a seu custo de oportunidade. Os fundos podem, eventualmente, ter prejuízos, pois atuam em mercados eficientes, nos quais as informações se refletem rapidamente sobre os preços dos títulos e estes espelham rigorosamente toda a informação disponível. Daí a ser necessário otimizar a estratégia de risco.

De acordo com Sharpe et al. (1995), o risco total de um título individual ou de uma carteira é o resultado da combinação do risco sistemático, parcela do risco que não pode ser eliminada pela diversificação, com o risco não-sistemático. A medida de risco sistemático geralmente utilizada é o coeficiente beta (ß), que mede a volatilidade dos retornos de um título com relação aos retornos de mercado como um todo.

A teoria básica relativa a risco e retorno é normalmente estudada nos modelos de equilíbrio (precificação) dos ativos financeiros. Estes se prestam a explicar o comportamento dos preços dos títulos e fornecer mecanismos de avaliação do investimento proposto ou realizado sobre o risco e o retorno de toda a carteira. Um dos modelos mais utilizados é o Capital Asset Pricing Model.

A teoria do Capital Asset Pricing Model estipula que a taxa de rentabilidade esperada dos ativos com risco é linearmente ligada a dois fatores comuns: a taxa livre de risco e a taxa de retorno esperado da carteira de mercado. Este modelo estabelece as relações de risco e retorno esperado para verificar se determinado título está sendo negociado dentro de seu preço justo. O prêmio pelo risco, que é 
igual à diferença entre o retorno esperado deste ativo e aquele do ativo livre de risco, mede a remuneração do risco que um investidor suporta, quando investe uma unidade de seu capital neste ativo (Gitman, 1997).

O retorno esperado de qualquer ativo pode ser dado pela equação:

$$
R_{i}=R_{f}+\left[\beta_{i} \times\left(R_{m}-R_{f}\right)\right]
$$

em que,

$R_{i}=$ retorno esperado do ativo i;

$R_{f}=$ retorno do ativo livre de risco;

$\beta_{i}=$ coeficiente beta ou índice de risco não diversificável para o ativo i;

$R_{m}=$ retorno de mercado.

Sendo o retorno exigido sobre um ativo $\left(\mathrm{R}_{\mathrm{i}}\right)$ uma função do beta $\left(\beta_{\mathrm{i}}\right)$, o qual mede o risco não-diversificável, quanto maior for o risco, maior será o retorno exigido.

No presente estudo, o beta foi calculado pelo modelo de mercado, cuja metodologia consiste na utilização da regressão linear simples do excesso de retorno mensal do título i (ou da carteira) sobre o excesso de retorno da carteira mercado $\left(\mathrm{R}_{\mathrm{m}}\right)$. Neste modelo, utiliza-se o excesso de rentabilidade dos ativos e não a rentabilidade em si, pois o que é realmente importante para o investidor é o retorno efetivo desse ativo decorrente da existência de risco.

\section{Dados e Amostra}

Os dados relativos aos investimentos de cada entidade foram obtidos por meio dos demonstrativos trimestrais, Demonstrativos Analíticos de Investimento e Enquadramento das Aplicações (DAIEA), fornecidos pelas entidades. Estes demonstrativos contêm os dados discriminados referentes à quantidade e valor de mercado de cada um dos títulos que compõem as carteiras de investimento dos fundos de pensão. Apenas os investimentos no mercado à vista foram utilizados neste estudo.

Como proxy para o retorno do ativo livre de risco e para o retorno da carteira de mercado foram utilizados o Certificado de Depósito Interfinanceiro (CDI) e o IBOVESPA, respectivamente. 
Devido à dificuldade de consecução dos dados das entidades de médio e pequeno porte, optou-se por uma amostra por acessibilidade, porém considerando a característica de representatividade, uma vez que estas entidades contemplavam, na coleta, 46,4\% do total de ativos dos fundos de pensão no Brasil. A amostra foi formada por 11 entidades fechadas de previdência complementar, sendo constituída por fundos de grande e médio porte. Dentre estes, 9 são patrocinados por empresas públicas e 2 por empresas privadas. Dos 10 maiores fundos de pensão do Brasil, 6 fazem parte da amostra.

O período analisado foi de janeiro de 1999 a março de 2001. O período de estudo não foi maior em função da indisponibilidade dos dados dessas entidades.

Tendo como base o total de ativos das entidades no início do período estudado, dividiu-se a amostra em 3 grupos, conforme mostra a Tabela 2 .

Tabela 2: Segmentação da Amostra de Acordo com o Número Total de Ativos

\begin{tabular}{c|c|c}
\hline Grupo & Total de ativos (em R\$) & Entidade \\
\hline \multirow{2}{*}{1} & Superior a 8 bilhões & $\mathrm{F}$ \\
& & $\mathrm{G}$ \\
2 & \multirow{3}{*}{ De 1,5 a 8 bilhões } & $\mathrm{H}$ \\
\hline \multirow{3}{*}{2} & & $\mathrm{E}$ \\
& & $\mathrm{J}$ \\
& & $\mathrm{K}$ \\
\hline \multirow{3}{*}{3} & De 70 milhões a 1,5 bilhões & $\mathrm{B}$ \\
& & $\mathrm{C}$ \\
& & $\mathrm{D}$ \\
\hline
\end{tabular}

Font: dados da pesquisa.

\section{Tratamento dos Dados}

Calculou-se o retorno de cada ação e posteriormente o retorno da carteira por meio da média ponderada dos retornos dos ativos individuais que a compõem.

Mensurou-se, conforme o modelo de mercado, o risco mensal, ou seja, o coeficiente beta, de cada ação das carteiras dos fundos de pensão no período 
analisado. Feito isto, calculou-se o risco sistemático de cada carteira em cada mês por meio da média ponderada dos betas de cada ação da carteira.

Assim, a partir do cálculo do risco da carteira de ações, aplicou-se o Capital Asset Pricing Model com o objetivo de estimar o retorno mensal das carteiras dos fundos.

Para a análise do período total (abril de 1999 a março de 2001) e dos dois subperíodos (abril de 1999 a março de 2000 e abril de 2000 a março de 2001), foi necessário utilizar um procedimento no qual as variáveis pudessem representar todo o período. Inicialmente, calculou-se o retorno médio observado (real) das carteiras de ações do período total e dos sub-períodos por meio de média aritmética simples.

Para o cálculo do retorno estimado de cada um dos três períodos propostos realizou-se a regressão linear simples do excesso de retorno mensal da carteira sobre o excesso de retorno mensal do índice de mercado, obtendo-se assim os respectivos betas. A partir dos betas calculados para o período total e para os dois subperíodos, foi possível estimar o retorno por meio do modelo CAPM.

Ressalta-se que o CDI dos períodos foi obtido por meio da média aritmética simples de suas rentabilidade mensais, não havendo diferença relevante entre a rentabilidade média obtida e as mensais observadas.

Como os dados referentes aos retornos de mercado mensais, representados pelo IBOVESPA, apresentavam grandes oscilações no período estudado, optouse pela utilização da mediana, visto que esta medida não é tão influenciada pelos valores extremos da amostra quanto a média, refletindo melhor o retorno de mercado.

\section{Discussão dos Resultados}

A análise dos resultados das regressões demonstrou que os testes estatísticos apresentaram, de modo geral, resultados significativos (Tabelas 3, 4 e 5). Os modelos de regressão atenderam ao nível de significância de 10\%; a estatística Durbin-Watson demonstrou não existir autocorrelação de primeira ordem; os resíduos apresentaram distribuição normal, conforme indicou o teste Jarque-Bera; e os $\mathrm{R}^{2}$ ajustados encontrados, em sua maioria, ficaram em torno de $80 \%$. 
Tabela 3: Resultados da Regressão do Período Abril de 1999 a Março de 2001

\begin{tabular}{|c|c|c|c|c|c|}
\hline Entidades & Constante & Rm-Rf & $\overline{\mathbf{R}^{2}}$ & Estatística Durbin-Watson & Jarque - Bera \\
\hline A & $\begin{array}{c}0,021116 \\
t=1,910433 \\
\text { Sig }=0,0692\end{array}$ & $\begin{array}{c}0,982564 \\
t=5,343659 \\
\text { Sig }=0,0000\end{array}$ & 0,545047 & 2,206188 & 0,632697 \\
\hline B & $\begin{array}{c}0,005521 \\
t=0,915970 \\
\mathrm{Sig}=0,3696\end{array}$ & $\begin{array}{c}0,877947 \\
\mathrm{t}=14,37266 \\
\mathrm{Sig}=0,000\end{array}$ & 0,899376 & 2,746721 & 1,282944 \\
\hline $\mathrm{C}$ & $\begin{array}{c}0,001353 \\
t=0,206416 \\
\text { Sig }=0,8384\end{array}$ & $\begin{array}{c}0,924458 \\
t=13,91650 \\
\text { Sig }=0,0000\end{array}$ & 0,893355 & 2,373291 & 0,553572 \\
\hline $\mathrm{D}$ & $\begin{array}{c}-0,017296 \\
t=-2,508906 \\
\text { Sig }=0,0200\end{array}$ & $\begin{array}{c}0,695625 \\
t=9,957456 \\
\text { Sig }=0,0000\end{array}$ & 0,810154 & 1,490252 & 0,089026 \\
\hline $\mathrm{E}$ & $\begin{array}{c}-0,019932 \\
t=-1,959314 \\
\text { Sig }=0,0629\end{array}$ & $\begin{array}{c}0,70283 \\
\mathrm{t}=6,817690 \\
\text { Sig }=0,0000\end{array}$ & 0,66414 & 2,011009 & 0,794593 \\
\hline $\mathrm{F}$ & $\begin{array}{c}0,004457 \\
\mathrm{t}=1,038677 \\
\mathrm{Sig}=0,3102\end{array}$ & $\begin{array}{c}0,592373 \\
t=13,62337 \\
\text { Sig }=0,0000\end{array}$ & 0,889208 & 2,060491 & 1,481614 \\
\hline G & $\begin{array}{c}0,004474 \\
\mathrm{t}=0,740781 \\
\mathrm{Sig}=0,4667\end{array}$ & $\begin{array}{c}0,653902 \\
t=10,684888 \\
\operatorname{Sig}=0,0000\end{array}$ & 0,831089 & 1,998692 & 2,240592 \\
\hline $\mathrm{H}$ & $\begin{array}{c}0,019346 \\
t=3,115375 \\
\mathrm{Sig}=0,0050\end{array}$ & $\begin{array}{c}0,576578 \\
t=9,162289 \\
\text { Sig }=0,0000\end{array}$ & 0,782911 & 1,980347 & 0,904731 \\
\hline I & $\begin{array}{c}0,004719 \\
t=0,573008 \\
\text { Sig }=0,5724\end{array}$ & $\begin{array}{c}0,804189 \\
t=9,636158 \\
\text { Sig }=0,0000\end{array}$ & 0,799748 & 2,497094 & 0,044079 \\
\hline $\mathrm{J}$ & $\begin{array}{c}0,005348 \\
\mathrm{t}=0,862849 \\
\mathrm{Sig}=0,3975\end{array}$ & $\begin{array}{c}0,845909 \\
t=13,46795 \\
\text { Sig }=0,0000\end{array}$ & 0,886914 & 1,545374 & 3,226129 \\
\hline K & $\begin{array}{c}0,016035 \\
t=1,859549 \\
\text { Sig }=0,0764\end{array}$ & $\begin{array}{c}0,540349 \\
t=6,183585 \\
\text { Sig }=0,0000\end{array}$ & 0,618173 & 2,48858 & 0,049294 \\
\hline
\end{tabular}

Fonte: dados da pesquisa

Nota: $\mathrm{t}$ = estatística $\mathrm{t}$

Sig = significância 


\section{Tabela 4: Resultados da Regressão com o Período de Abril de 1999 a Março de 2000}

\begin{tabular}{|c|c|c|c|c|c|}
\hline Entidades & Constante & Rm-Rf & $\mathbf{R}^{2}$ & Estatística Durbin-Watson & Jarque - Bera \\
\hline A & $\begin{array}{c}0,018818 \\
\mathrm{t}=0,834083 \\
\text { Sig }=0,4237\end{array}$ & $\begin{array}{c}0,767524 \\
t=3,191858 \\
\text { Sig }=0,0096\end{array}$ & 0,455121 & 2,797497 & 0,521059 \\
\hline B & $\begin{array}{c}0,010756 \\
t=1,030678 \\
\text { Sig }=0,3270\end{array}$ & $\begin{array}{c}0,776615 \\
t=6,982428 \\
\text { Sig }=0,0000\end{array}$ & 0,81278 & 2,982756 & 1,832228 \\
\hline $\mathrm{C}$ & $\begin{array}{c}-0,001463 \\
\mathrm{t}=-0,135813 \\
\text { Sig }=0,8947\end{array}$ & $\begin{array}{c}0,83899 \\
\mathrm{t}=7,305141 \\
\text { Sig }=0,0000\end{array}$ & 0,826403 & 2,628511 & 0,149126 \\
\hline D & $\begin{array}{c}-0,01776 \\
\mathrm{t}=-2,148397 \\
\mathrm{Sig}=0,0572\end{array}$ & $\begin{array}{c}0,51757 \\
\mathrm{t}=5,874243 \\
\mathrm{Sig}=0,0002\end{array}$ & 0,752846 & 1,723315 & 1,69004 \\
\hline $\mathrm{E}$ & $\begin{array}{c}-0,036782 \\
\mathrm{t}=-3,022229 \\
\mathrm{Sig}=0,0128\end{array}$ & $\begin{array}{c}0,732561 \\
t=5,647582 \\
\text { Sig }=0,0002\end{array}$ & 0,73744 & 1,807368 & 0,791552 \\
\hline $\mathrm{F}$ & $\begin{array}{c}0,00583 \\
\mathrm{t}=0,979925 \\
\mathrm{Sig}=0,3502\end{array}$ & $\begin{array}{c}0,570371 \\
\mathrm{t}=8,994829 \\
\mathrm{Sig}=0,0000\end{array}$ & 0,878997 & 2,084179 & 1,441762 \\
\hline G & $\begin{array}{c}0,006584 \\
t=0,890296 \\
\text { Sig }=0,3942\end{array}$ & $\begin{array}{c}0,453794 \\
t=5,757015 \\
\text { Sig }=0,0002\end{array}$ & 0,745035 & 2,733928 & 0,688947 \\
\hline $\mathrm{H}$ & $\begin{array}{c}0,022157 \\
t=1,980860 \\
\text { Sig }=0,0758\end{array}$ & $\begin{array}{c}0,432442 \\
t=3,627309 \\
\text { Sig }=0,0046\end{array}$ & 0,524989 & 1,879145 & 0,28704 \\
\hline I & $\begin{array}{c}0,000409 \\
t=0,029608 \\
\text { Sig }=0,9770\end{array}$ & $\begin{array}{c}0,731777 \\
\mathrm{t}=4,972815 \\
\mathrm{Sig}=0,0006\end{array}$ & 0,683261 & 2,744699 & 0,859466 \\
\hline $\mathbf{J}$ & $\begin{array}{c}0,003555 \\
t=0,304276 \\
\text { Sig }=0,7672\end{array}$ & $\begin{array}{c}0,824268 \\
t=6,618963 \\
\text { Sig }=0,0001\end{array}$ & 0,79558 & 1,307069 & 0,824769 \\
\hline $\mathrm{K}$ & $\begin{array}{c}0,022252 \\
t=1,326957 \\
\text { Sig }=0,2140\end{array}$ & $\begin{array}{c}0,420306 \\
t=2,351687 \\
\text { Sig }=0,0405\end{array}$ & 0,291713 & 2,174385 & 0,138037 \\
\hline
\end{tabular}

Fonte: dados da pesquisa

Nota: $\mathrm{t}$ = estatística $\mathrm{t}$

Sig = significância 


\section{Tabela 5: Resultados da Regressão com o Período de Abril de 2000 a Março de 2001}

\begin{tabular}{|c|c|c|c|c|c|}
\hline Entidades & Constante & Rm-Rf & $\overline{\mathbf{R}^{2}}$ & Estatística Durbin-Watson & Jarque - Bera \\
\hline A & $\begin{array}{c}0,017541 \\
t=1,945795 \\
\operatorname{Sig}=0,0803\end{array}$ & $\begin{array}{c}0,41818 \\
\mathrm{t}=4,792202 \\
\text { Sig }=0,0007\end{array}$ & 0,666315 & 1,207268 & 0,728245 \\
\hline B & $\begin{array}{c}0,005137 \\
\mathrm{t}=0,709417 \\
\mathrm{Sig}=0,4943\end{array}$ & $\begin{array}{c}0,945372 \\
\mathrm{t}=13,48730 \\
\text { Sig }=0,0000\end{array}$ & 0,942681 & 2,188081 & 1,243072 \\
\hline $\mathrm{C}$ & $\begin{array}{c}0,009282 \\
t=1,122650 \\
\text { Sig }=0,2878\end{array}$ & $\begin{array}{c}1,021884 \\
t=12,76801 \\
\text { Sig }=0,0000\end{array}$ & 0,936424 & 1,250861 & 0,344686 \\
\hline D & $\begin{array}{c}-0,006944 \\
t=-0,725678 \\
\mathrm{Sig}=0,4847 \\
\end{array}$ & $\begin{array}{c}0,86829 \\
t=9,374580 \\
\text { Sig }=0,0000 \\
\end{array}$ & 0,887621 & 1,222571 & 0,85849 \\
\hline E & $\begin{array}{c}-0,002342 \\
\mathrm{t}=-0,138901 \\
\mathrm{Sig}=0,8923\end{array}$ & $\begin{array}{c}0,768933 \\
\mathrm{t}=4,712088 \\
\mathrm{Sig}=0,0008\end{array}$ & 0,658425 & 2,41561 & 1,047367 \\
\hline $\mathrm{F}$ & $\begin{array}{c}0,004103 \\
t=0,569759 \\
\text { Sig }=0,5714\end{array}$ & $\begin{array}{c}0,605684 \\
t=8,688783 \\
\text { Sig }=0,0000\end{array}$ & 0,871337 & 2,077145 & 1,160055 \\
\hline G & $\begin{array}{c}0,013103 \\
t=1,902486 \\
\text { Sig }=0,0863\end{array}$ & $\begin{array}{c}0,833186 \\
\mathrm{t}=12,49734 \\
\operatorname{Sig}=0,0000\end{array}$ & 0,933808 & 1,210194 & 1,046173 \\
\hline $\mathrm{H}$ & $\begin{array}{c}0,024088 \\
\mathrm{t}=4,546759 \\
\operatorname{Sig}=0,0011\end{array}$ & $\begin{array}{c}0,698473 \\
\mathrm{t}=13,61982 \\
\operatorname{Sig}=0,0000\end{array}$ & 0,943734 & 2,547344 & 0,574378 \\
\hline I & $\begin{array}{c}0,013632 \\
t=1,278129 \\
\text { Sig }=0,2301\end{array}$ & $\begin{array}{c}0,89752 \\
\mathrm{t}=8,693121 \\
\mathrm{Sig}=0,0000 \\
\end{array}$ & 0,871451 & 2,14172 & 1,408841 \\
\hline $\mathrm{J}$ & $\begin{array}{c}0,008587 \\
t=1,243939 \\
\text { Sig }=0,2419\end{array}$ & $\begin{array}{c}0,876631 \\
t=13,11810 \\
\text { Sig }=0,0000 \\
\end{array}$ & 0,939588 & 2,021475 & 0,549123 \\
\hline K & $\begin{array}{r}0,015562 \\
\mathrm{t}=1,987414 \\
\mathrm{Sig}=0,0749\end{array}$ & $\begin{array}{r}0,620135 \\
\mathrm{t}=8,181647 \\
\mathrm{Sig}=0,0000\end{array}$ & 0,85703 & 2,862655 & 1,066682 \\
\hline
\end{tabular}

Fonte: dados da pesquisa

Nota: $\mathrm{t}=$ estatística $\mathrm{t}$

Sig = significância

Em alguns meses, ficou evidente o reflexo das oscilações bruscas da Bolsa de Valores nas carteiras das entidades. Nos meses de novembro e dezembro de 1999, junho e dezembro de 2000 e janeiro de 2001, todas as carteiras apresentaram o mesmo comportamento anormal evidenciado no mercado, caracterizado por grande elevação nas taxas de rentabilidade observadas. Já em setembro de 2000, fevereiro e março de 2001, constatou-se queda nos retornos em todos as carteiras das entidades da amostra. 
Por outro lado, em alguns meses, cujo retorno de mercado foi negativo, algumas entidades alcançaram taxas positivas de rentabilidade. Como exemplo podemos citar o mês de julho de 1999, quando o retorno de mercado foi de $-10 \%$ e as entidades $\mathrm{H}$ e $\mathrm{K}$ obtiveram retornos de $4 \%$ e 1,6\% respectivamente.

A partir da análise da rentabilidade observada no período total, verificou-se que as entidades $\mathrm{D}$ e $\mathrm{E}$ apresentaram os piores desempenhos entre as carteiras avaliadas; e as entidades A, H e K destacaram-se por possuírem carteiras com melhores desempenhos (Gráfico 2).

\section{Gráfico 2: Retorno Real Médio do Período Total das Carteiras de Ações dos Fundos de Pensão}

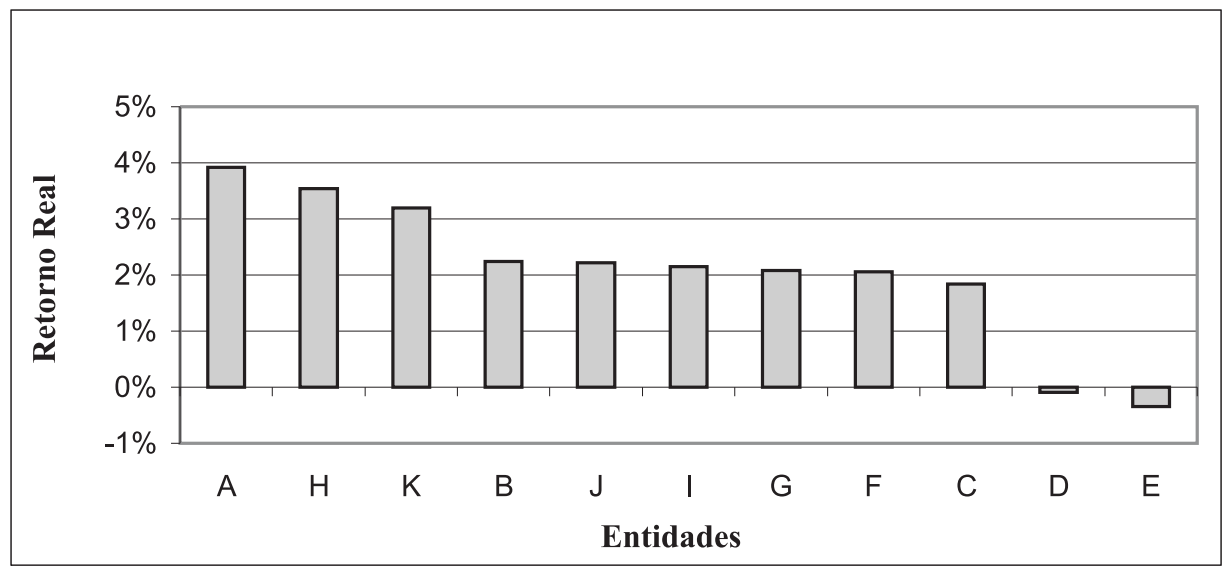

Fonte: dados da pesquisa.

Comparando os subperíodos, constatou-se que o desempenho das carteiras das entidades fechadas de previdência privada foi consideravelmente superior no primeiro período de estudo, em que o retorno médio mensal foi de 3,91\%, apresentando-se positivo em todas as entidades (Gráfico 3). Tal rentabilidade reflete o bom desempenho da Bolsa de Valores, cuja rentabilidade média foi de $4,7 \%$ durante o período.

Em contrapartida, o retorno médio mensal de $0,24 \%$ no segundo período ficou em conformidade com a multiplicidade de taxas de rentabilidade negativas apresentadas pela Bolsa de Valores no mesmo período. O IBOVESPA apresentou retorno médio de $-1,25 \%$ durante o período. Verificou-se que, entre as 11 entidades analisadas na amostra, apenas 6 obtiveram retorno positivo nesse período (Gráfico 4). 
Gráfico 3: Retorno Real Médio no $1^{\circ}$ Subperíodo das Carteiras de Ações dos Fundos de Pensão

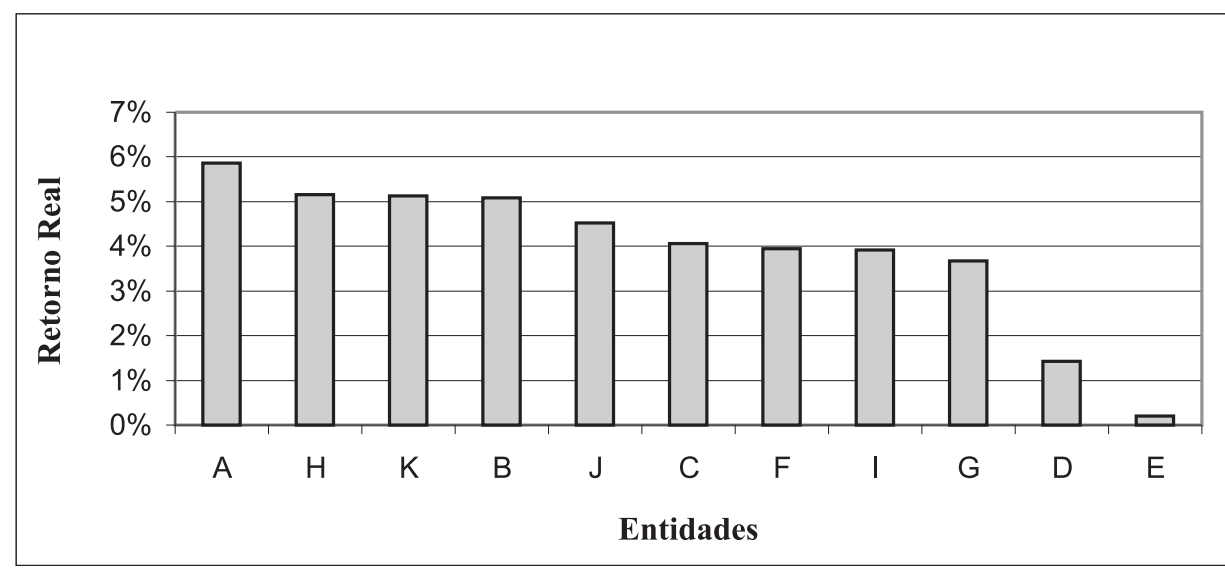

Fonte: dados da pesquisa.

\section{Gráfico 4: Retorno Real Médio no $2^{\circ}$ Subperíodo das Carteiras de Ações dos Fundos de Pensão}

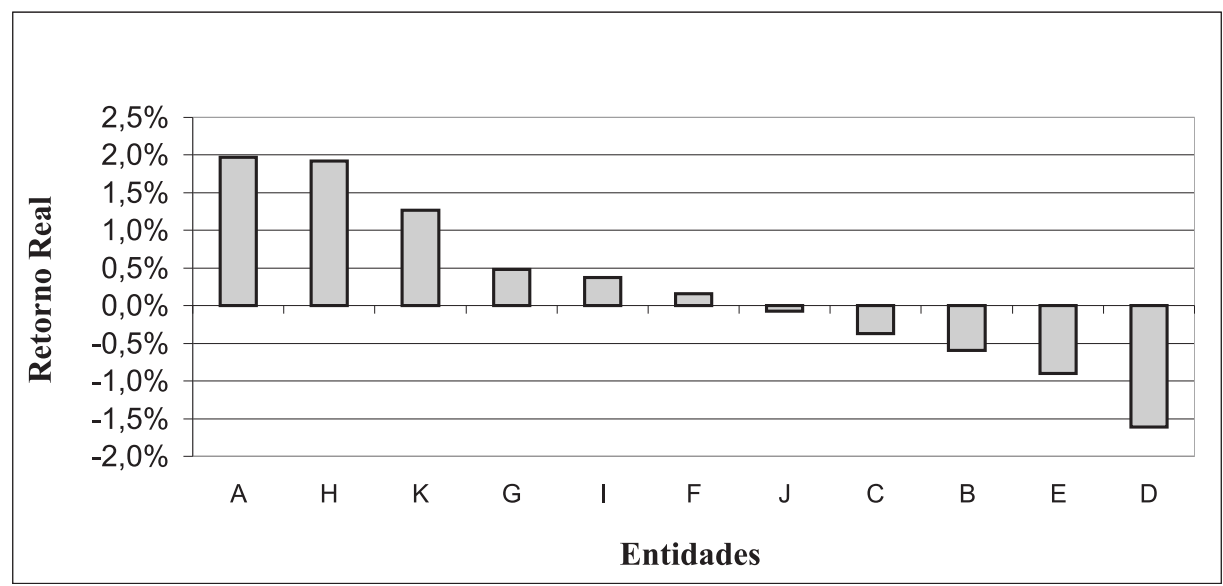

Fonte: dados da pesquisa.

A análise risco-retorno de cada segmento demonstrou que o retorno observado dos fundos possui uma relação direta com o seu tamanho. O retorno médio em cada um dos períodos foi maior no Grupo 1 (entidades F, G e H) e menor no Grupo 3 (entidades B, C, D e I). Quanto ao risco, observou-se que os fundos menores (Grupo 3) apresentaram os maiores riscos em cada um dos períodos. Já o Grupo 1 apresentou os menores riscos, com exceção do $2^{\circ}$ período, em que o risco observado no Grupo 2 (entidades A, E, J e K) foi inferior (Tabela 6). 
Tabela 6: Risco e Retorno por Segmento

\begin{tabular}{c|c|c|c}
\hline Período & Segmento & Risco & Retorno (\%) \\
\hline \multirow{3}{*}{ Período Total } & Grupo 1 & 0,61 & 2,56 \\
& Grupo 2 & 0,67 & 2,25 \\
& Grupo 3 & 0,83 & 1,54 \\
\hline \multirow{3}{*}{$1^{\text {o Período }}$} & Grupo 1 & 0,48 & 4,26 \\
& Grupo 2 & 0,69 & 3,93 \\
& Grupo 3 & 0,72 & 3,62 \\
\hline \multirow{2}{*}{$2^{\text {o Período }}$} & Grupo 1 & 0,71 & 0,85 \\
& Grupo 2 & 0,67 & 0,57 \\
& Grupo 3 & 0,94 & $-0,55$ \\
\hline
\end{tabular}

Fonte: dados da pesquisa.

A relação risco-retorno das carteiras de ações das entidades, efetuada por meio da regressão da variável representativa do risco (beta) com o retorno observado (real) de cada entidade, demonstrou uma relação inversa entre risco e retorno quando se analisa o período total e o $2^{\circ}$ período; no entanto apenas o segundo período atendeu ao nível de significância de 10\% (Tabela 7).

\section{Tabela 7: Resultados Estatísticos da Regressão Beta x Retorno Real}

\begin{tabular}{c|c|c}
\hline Período & Coef. de Determinação & Significância \\
\hline Período Total & $-3,125$ & 0,313 \\
$1^{\circ}$ período & 0,13 & 0,971 \\
$2^{\circ}$ período & $-4,339$ & 0,022 \\
\hline
\end{tabular}

Fonte: dados da pesquisa.

Os resultados demonstram que as entidades A, H e K, além de possuírem os maiores retornos, são também as mais eficientes em se tratando de gerenciar riscos, conseguindo uma combinação de maior retorno e menor risco, comparativamente aos outros fundos.

A contrastação dos retornos estimados com os respectivos retornos reais permitiu inferir que as carteiras dos fundos de pensão tiveram retorno satisfatório no que diz respeito a seus investimentos em ações. Com exceção das carteiras das entidades $\mathrm{D}$ e $\mathrm{E}$, todas apresentaram taxas de rentabilidade positivas e superiores às esperadas, ou seja, as carteiras de ações das entidades fechadas de previdência privada obtiveram retorno superior ao que seria justo em decorrência do risco incorrido por elas (Tabela 8). 
A contrastação dos retornos estimados com os retornos reais dos subperíodos demonstrou que a diferença das rentabilidades observadas nos dois períodos deve ser analisada concomitantemente à discrepante diferença nos seus retornos estimados, ou seja, tanto os retornos observados quanto os estimados, estes mais do que aqueles, foram significativamente inferiores no segundo período (Tabelas 9 e 10).

O fato do retorno estimado ter sido muito menor no segundo período pode ser explicado a partir da análise do desempenho do IBOVESPA e do CDI, durante o período de estudo. A taxa de retorno do mercado (obtida pela mediana) foi de 4,98\% no primeiro período e de $-5,20 \%$ no segundo. Por sua vez, o retorno livre de risco (obtido pela média aritmética simples) foi de 1,60\% e 1,27\% no primeiro e segundo período, respectivamente. No entanto, apesar de ambas as taxas apresentarem queda no desempenho durante o segundo período, é a diferença entre elas, ou seja, o excesso de retorno de mercado, que é relevante, uma vez que é este indicador que causa impacto direto no retorno esperado. Assim, a discrepância do prêmio pelo risco de mercado entre os períodos, 3,38\% no primeiro e $-6,47 \%$ no segundo, resultou em grande queda dos retornos esperados das carteiras das entidades no segundo período, garantindo-lhes um superávit entre o retorno real e o estimado das suas carteiras de ações.

\section{Tabela 8: Retorno Real Médio Mensal x Retorno Estimado Mensal das Carteiras de Ações dos Fundos de Pensão no Período de Março de 1999 a Março de 2001}

\begin{tabular}{c|c|c|c}
\hline \multicolumn{3}{|c}{ Período Total } \\
\hline Entidade & Risco (beta) & Retorno Estimado (\%) & Retorno Real (\%) \\
\hline A & 0,58 & 1,21 & 3,92 \\
B & 0,88 & 1,09 & 2,25 \\
C & 0,92 & 1,07 & 1,84 \\
D & 0,70 & 1,16 & $-0,09$ \\
E & 0,70 & 1,16 & $-0,35$ \\
F & 0,59 & 1,20 & 2,06 \\
G & 0,65 & 1,18 & 2,08 \\
H & 0,58 & 1,21 & 3,54 \\
I & 0,80 & 1,12 & 2,14 \\
J & 0,85 & 1,10 & 2,22 \\
K & 0,54 & 1,22 & 3,20 \\
\hline
\end{tabular}

Fonte: dados da pesquisa. 
Tabela 9: Retorno Real Médio Mensal x Retorno Estimado Mensal das Carteiras de Ações dos Fundos de Pensão no Período de Março de 1999 a Abril de 2000

\begin{tabular}{c|c|c|c}
\hline \multicolumn{3}{|c}{$\mathbf{1}^{\mathbf{0}}$ Período } \\
\hline Entidade & Risco (beta) & Retorno Estimado (\%) & Retorno Real (\%) \\
\hline A & 0,77 & 4,20 & 5,87 \\
B & 0,78 & 4,23 & 5,09 \\
C & 0,84 & 4,44 & 4,06 \\
D & 0,52 & 3,35 & 1,43 \\
E & 0,73 & 4,08 & 0,20 \\
F & 0,57 & 3,53 & 3,95 \\
G & 0,45 & 3,13 & 3,67 \\
H & 0,43 & 3,06 & 5,16 \\
I & 0,73 & 4,08 & 3,91 \\
J & 0,82 & 4,39 & 4,52 \\
K & 0,42 & 3,02 & 5,13 \\
\hline
\end{tabular}

Fonte: dados da pesquisa.

Tabela 10: Retorno Real Médio Mensal $x$ Retorno Estimado

Mensal das Carteiras de Ações dos Fundos de Pensão no Período de Maio de 2000 a Março de 2001

\begin{tabular}{c|c|c|c}
\hline \multicolumn{3}{|c}{$\mathbf{2}^{\mathbf{0}}$ Período } \\
\hline Entidade & Risco (beta) & Retorno Estimado (\%) & Retorno Real (\%) \\
\hline A & 0,42 & $-1,43$ & 1,97 \\
B & 0,95 & $-4,85$ & $-0,59$ \\
C & 1,02 & $-5,34$ & $-0,37$ \\
D & 0,87 & $-4,35$ & $-1,61$ \\
E & 0,77 & $-3,70$ & $-0,90$ \\
F & 0,61 & $-2,65$ & 0,16 \\
G & 0,83 & $-4,12$ & 0,48 \\
H & 0,70 & $-3,25$ & 1,92 \\
I & 0,90 & $-4,54$ & 0,38 \\
J & 0,88 & $-4,40$ & $-0,08$ \\
K & 0,62 & $-2,74$ & 1,27 \\
\hline
\end{tabular}

Fonte: dados da pesquisa. 


\section{Conclusão}

Os fundos de pensão podem atuar como agentes do desenvolvimento econômico ao investirem seus recursos de forma produtiva. Para efeito deste trabalho, foi considerado como investimento produtivo a aplicação de recursos nas empresas, seja por meio do mercado primário, seja por meio do mercado secundário. Acreditase que a compra de títulos no mercado secundário incentiva os negócios em bolsas de valores, estimulando a emissão de novas ações e até mesmo a abertura de capital, promovendo, portanto, o desenvolvimento econômico.

O Capital Asset Pricing Model foi utilizado neste estudo para avaliar o desempenho das carteiras de investimento em ações dos fundos de pensão, verificando, assim, a relação risco-retorno deles e o papel que desempenham na formação de poupança interna e na aplicação de recursos no setor produtivo. A mensuração e análise do desempenho das carteiras das entidades permitiu concluir que, no geral, os retornos reais superaram os retornos estimados. No entanto os resultados indicaram que há diferenciação nesse desempenho quando se segmentam os fundos por tamanho. Os maiores fundos apresentaram as maiores taxas de retorno e, no geral, os menores riscos.

Uma vez que o fim-último dos fundos de pensão consiste em garantir a concessão de benefícios aos seus participantes, o que implica empregar os recursos nas modalidades mais rentáveis, sempre levando-se em consideração o risco, podese dizer que o fato de os investimentos em ações possibilitarem retornos superiores aos esperados estimularia a priorização deles pelas entidades, o que geraria por um lado maior valor agregado ao fundo e, por outro, um incremento da poupança interna do país, respaldado pela aplicação eficiente dos recursos, ou seja, pelo investimento no setor produtivo.

Entretanto algumas medidas devem ser tomadas para que os fundos de pensão desempenhem papel mais relevante no financiamento do crescimento econômico brasileiro. Um incentivo ao incremento da participação da população nesses fundos seria importante na medida em que aumentaria o nível de poupança interna, a partir da disponibilização de maiores recursos para o aumento da capacidade produtiva. Por outro lado, a contribuição dos fundos para o crescimento econômico depende de políticas públicas adequadas. Tendo em vista que os requisitos e as regras para os investimentos dos fundos, fixados pelos órgãos de supervisão, aparecem como um dos principais condicionantes da distribuição das carteiras de ativos de fundos de pensão, os responsáveis pela elaboração da legislação pertinente aos limites de aplicações das entidades fechadas de previdência privada devem empenhar-se em que ela possibilite a otimização da alocação dos recursos. 
A possibilidade de a ação estatal se limitar à fiscalização e controle da saúde financeira das entidades deve ser considerada, uma vez que os limites de investimentos em renda variável impedem a otimização da alocação de recursos no que diz respeito aos investimentos no setor produtivo. As restrições deveriam ser eliminadas e aos administradores dos fundos de pensão deveria ser dada total liberdade para a definição de políticas de investimentos dos fluxos de receitas e dos recursos acumulados, o que permitiria maior aplicação dos recursos em renda variável, implicando, portanto, incremento do investimento produtivo.

Enfim, os fundos de pensão podem desempenhar importante papel na formação de poupança interna e no desenvolvimento da economia, na medida em que canalizem seus recursos para o setor produtivo. Visto que a ampliação desses investimentos está intimamente relacionada às políticas e ações governamentais, é imprescindível que estas atuem de forma a proporcionar incremento da participação desses fundos no financiamento do crescimento econômico brasileiro.

\section{Artigo recebido em 02.06.2003. Aprovado em 22.12.2003.}

\section{ReferÊnCias Bibliográficas}

BAIMA, F. R.

Análise de desempenho dos investimentos dos fundos de pensão no Brasil. Florianópolis, 1998. Dissertação (Mestrado em Engenharia de Produção) - Programa de Pós-Graduação em Engenharia de Produção, Universidade Federal de Santa Catarina, Santa Catarina.

CASTRO, H. O. P. et al.

Regimes complementares de previdência. Rio de Janeiro: FGV/ EPGE, 48p., 1994. Ensaios Econômicos n. 238.

CINTRA, M. A. M.

Frágil argumento. Jornal da Unicamp, Campinas, fev. 2000. Entrevista. Disponível em: <http:// www.unicamp.br/unicamp/ unicamp_hoje/ju/fev2000/pagina8Ju149.html>. Acesso em: 15 jun. 2002.

FEDERACIÓN IBEROAMERICANA DE BOLSAS DE VALORES

Poupança privada e desenvolvimento econômico mecanismos de estímulo e papel das Bolsas de Valores, Buenos Aires, 2002. Disponível em:<http://www.fiabv.org/fiabv/ a r c hivos / p d f / P o u p a n c a privada.PDF $>$. Acesso em: 20 mai. 2002.

FRANÇA, R. C.

A influência dos fundos de pensão para o crescimento econômico brasileiro. Belo Horizonte, 2002. Tese (Mestrado em Administração) Faculdade de Ciências Econômicas, Universidade Federal de Minas Gerais. 
GITMAN, L.

Princípios de administração financeira. 7. ed. São Paulo: Harbra, 1997.

INFORMAÇÕESMACROECONÔMICAS. Disponível em: <http:// www.abrapp.org.br/estatisticas/ internacional/estatística regional/ estatisticas_regionais.htm>. Acesso em 11 set. 2002.

MATIJASCIC, M.

Fundos de pensão e rearticulação da economia brasileira. Campinas: UNICAMP, 1994. Texto para discussão n.40.

MIRANDA, R. B.;

RODRIGUES Jr., W.;

SILVA, M. M.

Intermediação de poupança para investimento no setor produtivo. Brasília: IPEA, 1998. Texto para discussão n. 597.

MOTTA, J. R. S. T.

Uma análise da relação entre mercado de capitais e desenvolvimento. Brasília. Consultoria Legislativa, 2001. Disponível em: $<$ http://www.camara.gov.br/internet/ diretoria/con leg / es tudos / 011858.pdf.> Acesso em 03 jul. 2002.
PEREIRA, F;

MIRANDA, R. B.;

SILVA, M. M.

Os fundos de pensão como geradores de poupança interna. Brasília: IPEA, 1997. Texto para discussão n. 480.

SHARPE, W. F.;

ALEXANDER, G. J.;

BAILEY, J. V.

Investments. 5. ed. New Jersey: Prentice Hall, 1995.

\section{STUDART, R.}

Pension funds and the financing of productive investments: an analysis based on Brazil's recent experience. Santiago, 2000. Disponível em: <http:/ /www.ancepp.org.br/biblioteca/ cepal/eventocepalppt.htm>. Acesso em: 08 jan. 2002. 